\title{
Multi-resistant pseudomonas aeruginosa: study of risk factors for its detection at intensive care unit admission
}

\author{
S Puerto Corrales ${ }^{1 *}$, R Vara Arlanzón ${ }^{1}$, F Callejo-Torre ${ }^{1}$, JM Eiros Bouza ${ }^{2}$, MJ Coma del Corral ${ }^{3}$, ME Perea Rodríguez ${ }^{1}$, \\ M Martínez Barrios ${ }^{1}$, M Gero Escapa ${ }^{1}$, S Ossa Echeverri ${ }^{1}$, M del Valle Ortíz ${ }^{1}$, S Calvo Simal ${ }^{3}$, E Portugal Rodríguez ${ }^{1}$, \\ JA Fernández Ratero ${ }^{1}$, ENVIN-HELICS Study Group
}

From ESICM LIVES 2015

Berlin, Germany. 3-7 October 2015

\section{Introduction}

For both infection control (avoiding dispersion of multiresistant) and to ensure empirical antibiotic treatment is essential to be able to detect colonization/ infection by multi-resistant Pseudomonas aeruginosa (C/I- MRPa) at ICU admission.

\section{Objectives}

Identify risk factors for easy detection (without requiring access to medical history) for C/I- MRPa at ICU admission. Evaluate whether with the factors chosen after literature review and analyzed, it is possible to develop an effective predictive model.

\section{Methods}

From variables collected prospectively in ENVIN study (national nosocomial infection surveillance study), data was analyzed from 16950 patients admitted in 151 polyvalent ICU during the period from April to June in 2010, as a multipurpose cohort with univariable analysis and a multivariable logistic regression. Multi-resistant Pseudomonas aeruginosa, was defined as being resistant to three or more antipseudomonal families. The study variables are: age, gender, underlying disease, origin, urgent surgery, immunosuppression, immunodeficiency, neutropenia, surgical wound infection (superficial or deep) and skin and soft tissue infections.

\section{Results}

In the univariable analysis we found statistical relationship between C/I-MRPa at admission time in ICU and the

${ }^{1}$ Hospital Universitario de Burgos, Intensive Care, Burgos, Spain

Full list of author information is available at the end of the article variables: underlying disease, origin, immunodeficiency, neutropenia, superficial surgical wound infection or skin and soft tissue infection. In the multivariate analysis we identified as independent risk factors: underlying medical disease $(2,07(1,17-3,66) 0.01)$, immunosuppression $(3,22$ $(1,79-5,79)<0.001)$ and superficial surgical wound infection $(6,65(1,70-26) 0.006)$. Coronary artery disease acts as a protective factor $(0.26(0,07-0,92) 0.03)$. The predictive model globally considered, shows a moderate discriminating capacity (ABC-COR: 0.72;) 95\% CI (0,67-0,78).

\section{Conclusions}

There is an increase in the risk for C/I- MRPa at ICU admission in medical patients (2 times), immunosuppressed (3 times) or in those that present an infection of superficial surgical wound at the admission time in the unit (6 times). Coronary patients have lower risk. Despite assessing all variables described, we couldn't develop a satisfactory predictive model because of its fair global prediction capability. Risk factors described should be taken into account for future studies with similar approach.

\section{Authors' details}

${ }^{1}$ Hospital Universitario de Burgos, Intensive Care, Burgos, Spain. ${ }^{2}$ Hospital Clinico Universitario de Valladolid, Microbiology, Valladolid, Spain. ${ }^{3}$ Hospital Universitario de Burgos, Burgos, Spain.

Published: 1 October 2015

doi:10.1186/2197-425X-3-S1-A123

Cite this article as: Puerto Corrales et al: Multi-resistant pseudomonas aeruginosa: study of risk factors for its detection at intensive care unit admission. Intensive Care Medicine Experimental 2015 3(Suppl 1):A123. (c) 2015 Puerto Corrales et al.; This is an Open Access article distributed under the terms of the Creative Commons Attribution License (http://creativecommons.org/licenses/by/4.0), which permits unrestricted use, distribution, and reproduction in any medium, provided the original work is properly cited. 